\title{
Menentukan Titik Pemasangan Radio Wireless untuk Link Point to Point Dengan memanfaatkan Bot Telegram
}

\author{
Wartono'), Nafis Sururi2) \\ Universitas Amikom Jogjakarta \\ Jl. Ring Road Utara, Condong Catur, Depok -Sleman, Yogyakarta, \\ E-mail: wartana4@gmail.com, nafissururi@gmail.com
}

\begin{abstract}
Wireless network has become a basic need in digital era. In its development, wireless network that is commonly known as Wi-fi can be easily found in the offices, schools, or other public places from the town to the country side. But, some villages where optic fibers have not been available have not been able to access internet. For thet case, the writer divided those internet connections to the places where fiber optics werr not available using poin to poin protocol in wireless radio (WLAN) in $5.8 \mathrm{~Hz}$ frequency with bot telegram. Bot telegram was used to help determining the right position between teo radio wireless (WLANs) so the condition in the field could gain high signal strength, transmition, and connection with maximal troughtput
\end{abstract}

Keywords: Wireless Radio (WLAN), Point to point, Bot Telegram,

\begin{abstract}
Abstrak
Jaringan wireless sudah menjadi kebutuhan pokok diera digital ini, dalam perkembangannya jaringan wireless atau sering disebut wifi sudah banyak ditemukan dikantor, sekolahan atau tempat umum lainnya baik diperkoataan ataupun pedesaan. Namun beberapa wilayah desa yang khususnya belum dilalui jaringan kabel internet atau fiber optic belum bias mendapatkan akses internet. Maka dari itu penulis membagi koneksi jaringan internet tersebut ketempat-tempat yang belum dilalui kabel internet menggunakan protokol point to point pada radio wireless (WLAN) pada frekuensi $5.8 \mathrm{GHz}$ dengan bot telegram. Dimana bot telegram ini digunakan untuk membantu dalam penentuan dimana posisi yang tepat antara kedua radio wireless (WLAN) tersebut ditempatkan, sehingga didapatkan kondisi lapangan yang benar-benar los dan signal strength yang tinggi, serta menghasilkan koneksi dengan troughpout yang maksimal.
\end{abstract}

Kata kunci: Radio Wireless (WLAN), Point to point, Bot Telegram, 


\section{Pendahuluan}

Melihat

perkembangan

teknologi yang semakin canggih hampir semua peralatan membutuhkan koneksi internet agar dapat terhubung dengan alat yang lainnya. Untuk dapat menggunakan internet maka perlu koneksi antara client dengan server internet. Hal ini tidak menjadi permasalahan ketika sebuah Kantor atau instansi yang letaknya tidak jauh dari jalur internet yang berupa kabel internet ataupun fiber optic. Tetapi untuk mendapatkan koneksi internet tersebut menjadi masalah yang cukup serius untuk Kantor atau instansi yang letaknya cukup jauh dari jalur internet tersebut. Permasalahan ini bisa disebabkan karena jarak yang terlalu jauh dan tidak memungkinkan dengan menarik kabel dari sumber internet hingga ke tujuan dengan jarak yang melebihi ketentuan batas maksimal penggunaan panjang kabel. Maka alternativ yang dapat digunakan adalah dengan membuat link nirkabel point to point untuk menggantikan fungsi kabel. Didalam makalah ini membahas sedikit banyak tentang bagaimana menentukan titik pemasangan radio wireless untuk membuat link point to point dengan memanfaatkan bot telegram berupa BotRF yang nantinya dari bot telegram tersebut akan memberikan informasi yang kita perlukan sesuai dengan parameter-parameter yang kita inputkan, sehingga akan menghasilkan link koneksi yang maksimal.

Salah satu aspek yang
terpenting dalam perencanaan
hubungan nirkabel adalah penentuan
atenuasi antara transmitter dan receiver
yang pada akhirnya menentukan
kelayakan suatu link yang diberikan.
Banyak program komersial yang
ditawarkan untuk memecahkan masalah
ini, kebanyakan program tersebut
menggunakan peta elevasi digital.

Tetapi program tersebut cukup mahal bahkan dalam penggunaanyapun dibatasi pada radio dan antenna jenis pabrikan tertentu. Vendor seperti Motorola, Ubiquiti Networks, Cambium dan Mimosa (dan lain sebaginya), menawarkan tool propagasi radio secara gratis. Tetapi dalam penggunaanya secara umum tergolong rumit, dan tool tersebut biasanya hanya digunakan sesuai dengan produk antena dari vendor tersebut. Untuk menggunakannya user harus mendaftarkan pada situs dari vendor yang dipakai dan kebanyakan tool-tool tersebut berbasis web dan belum bisa digunakan pada mobile device.

Bot telegram merupakan program opensource yang dapat digunakan sebagi pengukur kualitas link point to point dari kedua sisi radio. Program ini dapat berjalan pada semua jenis operating system baik mobile maupun desktop dan tidak membutuhkan banyak paket data untuk menggunakannya. Bahkan dalam penggunaanya pada mobile device kita dapat memanfaatkan GPS yang ada pada mobile tersebut sehingga secara otomatis mendeteksi lokasi posisi satu titik pada device tersebut berada. Bot telegram menyediakan fasilitas diantaranya simulasi profil medan pada tempat yang berbeda, nilai index bias, path los pada link point to point dan mampu menunjukkan dengan antarmuka yang mudah dipahami.

\section{Tinjauan Pustaka}

1. Radio Wireless (WLAN)

(Wireless Lokal Area Network) Merupakan jaringan computer yang menggunakan gelombang atau frekuensi radio sebagai perantara untuk mengirim atau menerima data. Berdasarkan IEEE (Institude of Electrical and Electronics Engineering) berikut generasi-genarasi dari WLAN : 
802.11a, IEEE 802.11b, IEEE 802.11g, $802.11 \mathrm{n}$ dan IEEE 802.11ac

\author{
a. IEEE 802.11-1999 (802.11a dan \\ 802.11b)
}

IEEE 802.11-1999 merupakan amandemen yangpertama kali dilakukan terhadap standar IEEE 802.11-1997. Standar ini mendefnisikan tentang protokol daninterkoneksi peralatan yang kompatibel untuk memfasilitasipertukaran data via udara baik radio maupun infrareddalam lingkungan jaringan area lokal menggunakanmekanisme Carrier Sense Multiple Access with CollisionAvoidance (CSMA/CA) pada lapisan MAC untukmendukung operasi pertukaran data baik menggunakanAP atau secara independen. Pada lapisan MAC. Standar IEEE 802.11-1999 terdiri dari dua supplemenyaitu $802.11 a$ dan 802.11b. IEEE 802.11a merupakanekstensi untuk HigherSpeed Physical Layer yangberoperasi pada pita frekuensi 5 $\mathrm{GHz}$, sedangkan IEEE802.11b merupakan ekstensi untuk HigherSpeedPhysical Layer yang beroperasi pada pita frekuensi2,4 GHz. Standar 802.11a menetapkan OFDM sebagaiteknik penyebaran spektrum radio dengan tujuan untukmendukung datarate sampai dengan $54 \quad$ Mbps denganmenggunakan alokasi pita frekuensi $5 \mathrm{GHz}$. Berbedadengan saudara kembarnya, IEEE 802.11b menetapkanbahwa metode penyebaran spektrum radio menggunakanHR/DSSS untuk mendukung peningkatan data ratesampai dengan 11 Mbps yang bekerja pada pita frekuensi2,4 GHz.Meskipun 802.11a menjanjikan data rate yang lebihbesar, namun sampai dengan 802.11-1999 dirilis, standarini kurang mendapatkan perhatian dan simpati daripasar (vendor) dikarenakan faktor jarak jangkauan yangrendah, faktor harga dan keterbatasan kemampuannyauntuk mendukung kelas pengguna enterprise sepertipermasalahan konektivitas dan interferensi radio yangsangat signifkan serta tidak dapat memenuhi keinginanpengguna kelas enterprise untuk memanfaatkan teknologijaringan nirkabel ini sebagai pengganti jaringan kabel.Sebaliknya para vendor perangkat jaringan lebih tertarikpada standar $802.11 \mathrm{~b}$ dikarenakan standar ini menjanjikanpeningkatan datarate sampai dengan 11 Mbps. Walaupun datarate yang ditetapkan oleh 802.11a lebih besar, namun802.11b dinilai kinerjanya lebih stabil dari sisi teknologiradio dan lebih rasional dari sisi harga, sehingga 802.11 bsangat signifkan mendominasi keseluruhan pasar,khususnya untuk kelas SMB .

b. IEEE 802.11g-2003

Tantangan utama dalam pengembangan awal teknologiWLAN adalah konektivitas dan interferensi radio. Namundisisi lain yang dihadapi adalah tuntutan pasar terhadapteknologi ini meningkat secara drastis. Diakui atau tidak,teknologi ini mulai merubah paradigma dalam penggunaanjaringan sebagai media transfer data. Pasar menilai bilateknologi ini mampu meningkatkan kestabilan hal dalamkonektivitas dan mampu menghasilkan throughput yangbesar, maka tidak mustahil WLAN akan merebut pasarjaringan berbasis kabel secara signifkan .Oleh karena itu, IEEE working group mulai mengajukanproposal perubahan terhadap standar WLAN 
sebelumnya,khususnya untuk mengakomodir permintaan pasar untukthroughput yang lebih baik. Setelah menjalani perdebatanyang panjang, pada tahun 2003 IEEE memutuskanuntuk mengeluarkan perubahan terhadap standar802.111999, dengan menetapkan standar baru 802.11g-2003. Munculnya standar ini dipicu oleh keterbatasan interoperabilitas $802.11 \mathrm{a}$ yang beroperasi dengan OFDM pada pita frekuensi $5 \mathrm{Ghz}$, dimana banyak perangkatnirkabel yang tidak kompatibel dengan standar tersebut. Namun demikian, secara mendasar 802.11g-2003 tidakmengganti standar sebelumnya, namun mengambilmanfaat dari metode OFDM sehingga PHY dapatditingkatkan. Standar $802.11 \mathrm{~g}$ dinamakan dengan "FutherHigher Data Rate Extension in the 2,4 GHz band". Standarini menetapkan metode penyebaran spektrum radiomenggunakan OFDM yang dapat mendukung dataratesampai dengan 54 Mbps dan beroperasi pada pita frekuensi2.4 GHz.Pemanfaatan OFDM pada pita frekuensi 2.4 GHzdinilai dapat meningkat throughput dan kestabilan koneksiWLAN. Perubahan ini juga berdampak signifkan terhadapkenaikan datarate dimana sebelumnya $\quad 802.11 \mathrm{~b}$ HR/DSSShanya mendukung 1,2 , 5.5, dan 11 Mbps, namun denganmunculnya $802.11 \mathrm{~g}$ terdapat opsi penambahan datarateuntuk pengintegrasian DSSS/OFDM sehingga ExtendedRate PHY (ERP PHY) dapat mendukung 6, 9, 12, 18,24, 36, 48, and 54 Mbps. DSSSOFDM adalah opsi yangdisediakan $802.11 \mathrm{~g}$ dan merupakan sebuah sistem modulasihybrid untuk mengkombinasikan sebuah preamble danheader DSSS dengan sebuah muatan transmisi OFDM(OFDM payload transmission). IEEE 802.11gERP PHY menyediakan kompatibilitas terhadap DSSS,

sehingga memungkinkan proses migrasi dari perangkatdengan standar 802.11 ke perangkat $802.11 \mathrm{~g} \quad(802.11 \mathrm{~b} / \mathrm{g}$ 2,4 Ghz).Muncul dengan sejumlah spesifkasi yang sangatmenjanjikan telah menjadikan teknologi jaringan nirkabelberbasis $\quad 802.11 \mathrm{~g}-2003$ mampu untuk membuat pasarWLAN tumbuh dengan cepat. Pasar menganggap bahwateknologi WLAN ini telah memenuhi kebutuhan dasar parapenggunanya. $\quad 802.11 \mathrm{~g}$ merupakan standar yang sangatpopuler sehingga sering disebut-sebut dengan singkatan54g, dimana para penggunanya dapat mengadopsi solusiWLAN ini untuk memperoleh konektivitas dan mobilitasyang fleksibel serta pengembangannya dapat dilakukandengan harga yang rendah dibandingkan dengan LANkonvensional berbasis kabel

c. IEEE 802.11n-2009

Peningkatan berbagai fungsionalitas WLAN telahmembawa perubahan terhadap gaya hidup manusiamodern. Penggunaan gadget seperti tablet PC dansmartphone seolah-olah menjadi style dan trend barudalam kehidupan manusia. Peningkatan terhadap datarateWLAN yang mencapai $54 \mathrm{Mbps}$ telah mengarahkan pasarteknologi ini secara tumbuh dengan sangat cepat danmerambah kesemua sektor di kelas SMB bahkan kelasenterprise mulai tertarik untuk melirik teknologi ini.Namun kapasitas datarate masih menjadi perhatian utamapengguna teknologi 
ini. Setelah $802.11 \mathrm{~g}$ ditetapkan, IEEEworking group menginisiasi proyek yang menargetkan dataratesebagai sasaran utama dalam pengembangan WLAN lanjutan. Akhirnya pada kuartal keempat tahun 2009, IEEE menetapkan standar IEEE $802.11 n$ 2009 sebagai standar tambahan teknologi WLAN. Standar ini merupakan amandemen kelima dengan judul "Enhancements for Higher Throughput (HT)". IEEE 802.11n merupakan proyek pertama dimana datarate diprioritaskan diatas lapisan MAC. Standar ini menyediakan fungsionalitas WLAN ke penggunanya setingkat diatas dengan penggunaaan teknologi Fast Ethernet (802.3u). Fast Ethernet merupakan teknologi jaringan kabel yang mampu mengirimkan data penggunanya dengan kecepatan 100 Mbps, dimana 802.11n mampu mentransmisikan data dengan kecepatan sampai dengan 600 Mbps. Kapasitas throughput yang besar diharapkan mampu meningkatkan pengalaman pengguna untuk menjalankan aplikasi multimedia seperti video streaming dan games beresolusi tinggi. IEEE 802.11n juga diharapkan mampu membuka dan meningkatkan segmen pasar baru untuk teknologi WLAN. IEEE 802.11n PHY menggunakan HT-OFDM yang dapat beroperasi pada pita frekuensi 2.4 $\mathrm{GHz}$ dan $5 \mathrm{GHz}$. Fitur utama dari standar IEEE 802.11n adalah kapabilitas dari Multiple Input Multiple Output (MIMO) untuk meningkatkan datarate sehingga mencapai jumlah ratusan mega bit per detik. Teknik MIMO memanfaatkan penggunaan beberapa antena untuk meningkatkan jarak, kehandalan dan kecepatan pen-transmisian data
Konsep MIMO memungkinkan aliran data dapat dikirim sampai dengan empat stream secara bersamaan baik menggunakan saluran $20 \mathrm{MHz}$ atau $40 \mathrm{MHz}$ melalui empat antena. Penggunaan MIMO pada $802.11 \mathrm{n}$ mengimplementasikan spatial multiplexing, sehingga secara dramatis dapat meningkatkan kapasitas throughput. Implementasi dari spatial multiplexing akan mengizinkan pengiriman dan penerimaan data stream secara terpisah (spatial streams). IEEE $802.11 \mathrm{n}$ menetapkan bahwa maksimum penggunaan hanya empat transmitter pada sisi stasiun (STA) pengirim dan empat receiver pada STA penerima. Meskipun $802.11 \mathrm{n}$ menggunakan teknik penyebaran spektrum radio berbasis OFDM, teknologi WLAN ini menyediakan kompatibilitas untuk proses pengintegrasian perangkat WLAN 802.11a, 802.11b dan $802.11 \mathrm{~g}$ dengan perangkat $802.11 \mathrm{n}$. Hal ini dimungkinkan karena pada saat standar ini diratifkasi tetap menyediakan beberapa opsi kelaskelas modulasi yang meliputi: OFDM, $\mathrm{HR} /$ DSSS, ERP-PBCC, DSSSOFDM, HT-OFDM. Oleh karena itu, para pengguna jaringan nirkabel yang sudah menginvestasikan perangkat WLAN yang berbasis pada standar sebelumnya tetap berpeluang melakukan pengembangan jaringan lanjutannya dengan menggunakan $802.11 \mathrm{n}$ tanpa perlu khawatir dengan interoperabilitas dan kompatibilitas

d. IEEE 802.11ac-2013

Generasi ac adalah genarasi standart terbaru yang dimiliki oleh jaringan kabel yang sudah mencapa iratusan giga bit per detik, IEEE working group kembali menginisiasi standar untuk giga bit WLAN. 
Padaawal tahun 2014, IEEE akhirnya merilis standar baruuntuk memperkaya khasanah standarstandar WLANsebelumnya dengan nama IEEE 802.11ac2013.Munculnya 802.11ac membuka peluang besar bahwakinerja teknologi jaringan area lokal nirkabel ini dapatditingkatkan untuk mencapai 1 Gbps.

Tabel 1. Perbedaan standar IEE $802.11 \mathrm{a} / \mathrm{b} / \mathrm{g} / \mathrm{h} / \mathrm{ac}$

\begin{tabular}{|c|c|c|c|c|}
\hline Protocol & $\begin{array}{c}\begin{array}{c}\text { freku } \\
\text { ensi }\end{array} \\
\end{array}$ & $\begin{array}{l}\text { Band } \\
\text { witdh }\end{array}$ & $\begin{array}{c}\text { Stream Data } \\
\text { Rate } \\
\end{array}$ & \multirow[t]{2}{*}{ Modulations } \\
\hline & GHz & MHz & Mbit/s & \\
\hline 802.11 & 2.4 & 22 & 1,2 & DSSS, FHSS \\
\hline $\mathrm{a}$ & 5 & 20 & $\begin{array}{l}6,9,12,18 \\
24,36,48,54\end{array}$ & OFDM \\
\hline $\mathrm{b}$ & 2,4 & 22 & $1,2,5.5,11$ & DSSS \\
\hline $\mathrm{g}$ & 2,4 & 20 & $\begin{array}{l}6,9,12,18, \\
24,36,48,54\end{array}$ & OFDM \\
\hline $\mathrm{n}$ & $\begin{array}{l}2,4 \quad / \\
5\end{array}$ & $\begin{array}{l}20 / \\
40\end{array}$ & $\begin{array}{l}\text { Up to } 288.8 \\
(20 \mathrm{MHz}) \\
\mathrm{Up}_{\mathrm{p}} \text { to } 600(40 \\
\mathrm{MHz})\end{array}$ & \multirow[t]{2}{*}{$\begin{array}{l}\text { MIMO- } \\
\text { OFDM }\end{array}$} \\
\hline ac & 5 & $\begin{array}{l}20 / 40 \\
/ 60 / 1 \\
60\end{array}$ & $\begin{array}{l}\text { Up to } 346.8 \\
(20 \mathrm{MHz}) \\
\mathrm{Up} \text { to } 800(40 \\
\mathrm{MHz}) \\
\mathrm{Up} \text { to } 1733.2 \\
(80 \mathrm{MHz}) \\
\mathrm{Up} \text { to } 3466.8 \\
(160 \mathrm{MHz})\end{array}$ & \\
\hline
\end{tabular}

2. Topologi Jaringan WLAN

Beberapa jenis topologi jaringan WLAN seperti dibawah ini [1]:

a. Jaringan Ad Hoc

Jaringan Ad Hoc merupakan suatu jaringan yang terdiri dari dua atau lebih piranti wireless yang berkomunikasi secara langsung satu sama lain. Sinyal yang dihasilkan oleh interface adapter Jaringan Wifi adalah berarah Omni keluar ke rentang jangkauan yang dipengaruhi oleh faktor-faktor lingkungan, dan juga sifat dari piranti yang terlibat. Jangkauan ini disebut sebagai suatu area layanan dasar (BSA - Basic Service Area).

Jika dua piranti berdekatan pada jangkauan satu sama lain, mereka bisa berkomunikasi satu sama lain, dan segera membentuk 2 node jaringan. Piranti jaringan yang berada pada area layanan dasar disebut suatu set layanan dasar (BSS - Basic Service Set).

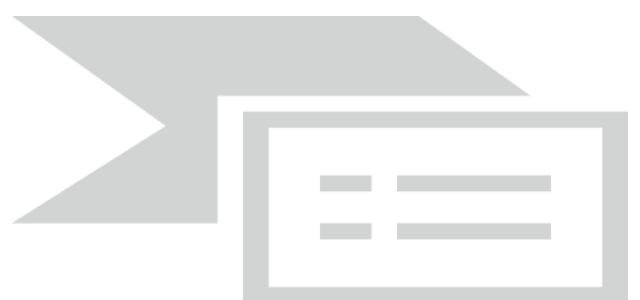

Gambar 1. Jaringan Ad Hoc

Jika ada satu lagi piranti wireless mendekat masuk dalam jangkauan BSA ini juga bisa berpartisipasi dalam jaringan. Akan tetapi jaringan $\mathrm{Ad} \mathrm{Hoc}$ tidaklah transitive, artinya jika dua piranti $A$ dan $B$ saling berkomunikasi dalam jangkauan piranti $A$, maka jika ada satu piranti C masuk dalam jangkauan piranti $B$ tetapi tidak masuk dalam jangkauan $A$, maka piranti $C$ tidak bisa berkomunikasi dengan piranti $\mathrm{A}$.

Berbeda dengan jaringan infrastruktur, jaringan ad-hoc tidak membutuhkan sebuah wireless lan untuk menghubungkan masingmasing komputer dan topologi jaringan yang terbentuk adalah jaringan mesh.

Berikut adalah beberapa keuntungan dari sebuah jaringan wireless ad-hoc:

1) Jaringan wireless Ad-Hoc sangat sederhana dalam mensetup nya.

2) Jaringan Ad-Hoc adalah cepat. Rate throughputnya antar adapter dua kali lebih cepat daripada anda menggunakan wireless access point dalam topology infrastcruture. 
b. Jaringan Infrastruktur

Jaringan infrastructure merupakan jaringan yang menggunakan suatu piranti Wifi yang disebut Access Point (AP) sebagai suatu bridge antara piranti wireless dan jaringan kabel standard. Konsep jaringan infrastruktur dimana untuk membangun jaringan ini diperlukan wireless lan sebagai pusat.

Wireless lan memiliki SSID sebagai nama jaringan wireless tersebut, dengan adanya SSID maka wireless lan itu dapat dikenali. Pada saat beberapa komputer terhubung dengan SSID yang sama, maka terbentuklah sebuah jaringan infrastruktur.

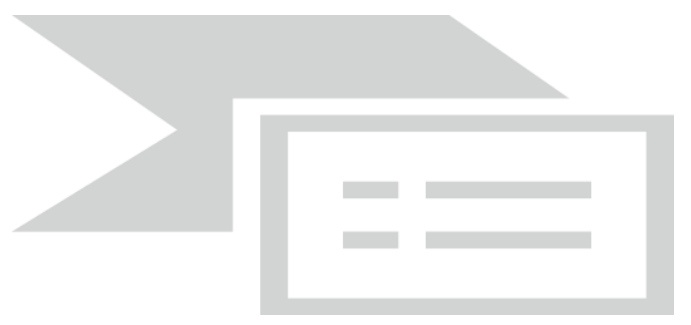

Gambar 2 . Jaringan Infrastruktur

Terlihat bahwa beberapa komuputer dihubungkan oleh satu wireless Lan, disini toplogi jaringan yang terbentuk adalah topologi star.

\section{Protokol Jaringan}

Protokol Jaringan adalah perangkat aturan yang digunakan dalam jaringan, Protokol adalah aturan main yang mengatur komunikasi diantara beberapa komputer di dalam sebuah jaringan sehingga komputer-komputer anggota jaringan dan komputer berbeda platform dapat saling berkomunikasi. semua jenis-jenis jaringan komputer menggunakan protokol. Aturan-aturan Protokol adalah termasuk di dalamnya petunjuk yang berlaku bagi cara-cara atau metode mengakses sebuah jaringan, topologi fisik, tipe-tipe kabel dan kecepatan transfer data. Dalam jaringan terdapat banyak jenis dari protokol diantaranya :TCP/IP
(Transmission Control Protocol/Internet Protocol),UDP ( User Datagram Protokol), Domain Name System (DNS), Point-to-Point Protocol, Serial Line Internet Protocol, Internet Control Message Protocol (ICMP), dan masih banyak lainnya. Dari sekian banyak protokol jaringan yang ada dalam makalah ini digunakan untuk mengkoneksikan dua device WLAN menggunakan protokol point to point dan dapat dilihat pada gambar 3 dibawah ini:

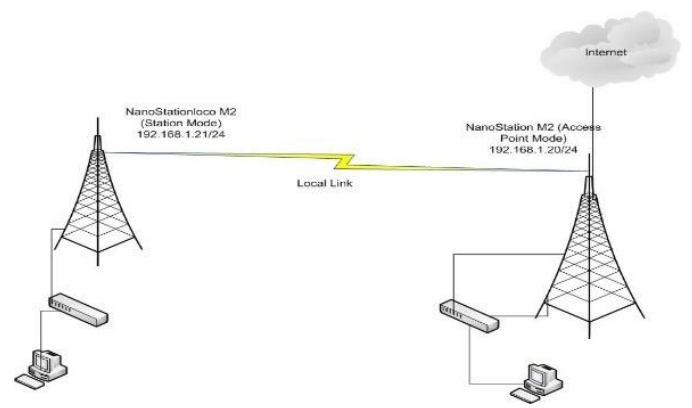

Gambar 3. Jaringan P2P / PPP (Pointto-Point Protocol)

Point-to-Point Protocol (sering disingkat menjadi PPP) adalah sebuah protokol enkapsulasi paket jaringan yang banyak digunakan pada wide area network (WAN). Protokol ini merupakan standar industri yang berjalan pada lapisan datalink dan dikembangkan pada awal tahun 1990-an sebagai respons terhadap masalah-masalah yang terjadi pada protokol Serial Line Internet Protocol (SLIP), yang hanya mendukung pengalamatan IP statis kepada para kliennya. Dibandingkan dengan pendahulunya (SLIP), PPP jauh lebih baik, mengingat kerja protokol ini lebih cepat, menawarkan koreksi kesalahan, dan negosiasi sesi secara dinamis tanpa adanya intervensi dari pengguna. Selain itu, protokol ini juga mendukung banyak protokol-protokol jaringan secara simultan. 
4. Telegram API

Telegram menyediakan 2 bentuk API, API yang pertama adalah klien IM Telegram, yang berarti semua orang dapat menjadi pengembang klien IM Telegram jika diinginkan. Ini berarti jika seseorang ingin mengembangkan Telegram versi mereka sendiri mereka tidak harus memulai semua dari awal lagi. Telegram menyediakan source code yang mereka gunakan saat ini. Tipe API yang kedua adalah Telegram Bot API. API jenis kedua ini memungkinkan siapa saja untuk membuat bot yang akan membalas semua penggunanya jika mengirimkan pesan perintah yang dapat diterima oleh Bot tersebut. Layanan ini masih hanya tersedia bagi pengguna yang menggunakan aplikasi Telegram saja. Sehingga pengguna yang ingin menggunakan Bot harus terlebih dahulu memiliki akun Telegram. Bot juga dapat dikembangkan oleh siapa saja.

\section{Metode Pengiriman yang} Disediakan oleh Telegram Bot API

Ada beberapa metode yang dapat digunakan untuk merancang sebuah Bot di Telegram [4]. Beberapa diantaranya adalah:
$\square$ sendMessage
$\square$ forwardMessage
$\square$ sendPhoto
$\square$ sendAudio
$\square$ sendDocument
$\square$ sendSticker
$\square$ sendVideo
$\square$ sendVoice
$\checkmark$ sendLocation
sendVenue
sendContact
sendChatAction
$\square$ getUserProfilePhotos
$\square$ getFile
kickChatMember
$\square$ leaveChat
$\square$ unbanChatMember
$\square$ getChat

\section{$\square$ getChatAdministrator \\ $\square$ getChatMember}

Bot juga dapat menggunakan custom keyboard untuk penggunanya. Hal ini akan mempermudah interaksi antara bot dan penggunanya. Semua dasar pengiriman data yang digunakan oleh server Telegram akan menggunakan JSON, sehingga pengembang bot harus juga menggunakan bentuk data JSON. Bot Telegram tidak terbatas oleh bahasa pemrograman. Hampir semua bahasa pemrograman bisa digunakan untuk merancang suatu bot. Telegram juga menyediakan contoh bot yang menggunakan berbagai bahasa pemrograman.

\section{Metode Penelitian}

Adapun langkah - langkah yang dilakukandalam pembuatan jurnal ini adalah sebagaiberikut :

\section{Survey Lokasi}

Sesuai dengan latar belakag masalah lokasi yang digunakan untuk penentuan titik pemasangan radio wireless adalah daerah yang rural yaitu dusun gobang desa banyurip kecamatan jenar kabupaten sragen yang seperti ditunjukkan pada gambar dibawah ini:

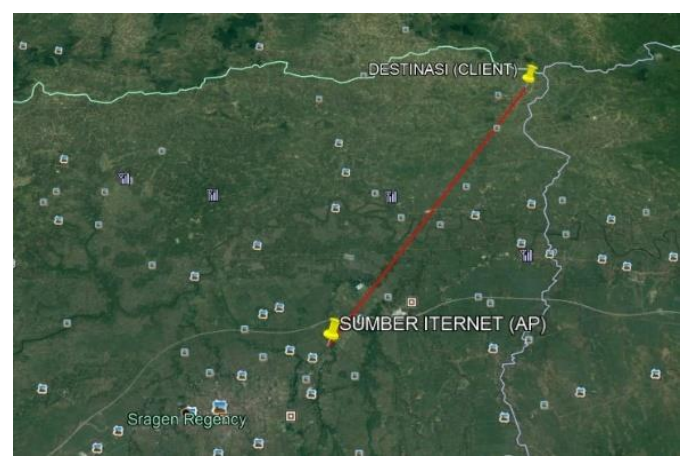

Gambar 4. Jarak Sumber Internet (sebagai AP) dari Ngrampal, Sragen Kota dengan tujuan (Sebagai client) Desa Banyurip Jenar 
Peta yang ditunjukkan pada gambar 4 menunjukkan lokasi dari sisi akses point dengan sisi client untuk membuat link point to point. Dimana akses point (Sumber internet) berada pada titik kordinat $7^{\circ} 24^{\prime} 09.7^{\prime \prime S} \quad 111^{\circ} 03^{\prime} 23.9^{\prime \prime} \mathrm{E}$ (7.402694, 111.056639) dan Client (Destinasi) berada pada titik kordinat 7¹6'27.1"S 11108'23.7"E (-7.274197, 111.139917).

2. Simulasi Bot Telegram (BotRF)

Setelah melakukan survey pada lokasi dan mendapatkan titik kordinat dari kedua sisi AP dan Client maka hal selanjutnya yang dilakukan adalah mensimulasikan dengan memasukkan parameter-parameter seperti: nama radio, tinggi radio dari sisi AP dan client, Frekuensi yang digunakan, kemudian titik koordinat dari kedua sisi menggunakan bot telegram berupa BotRF.

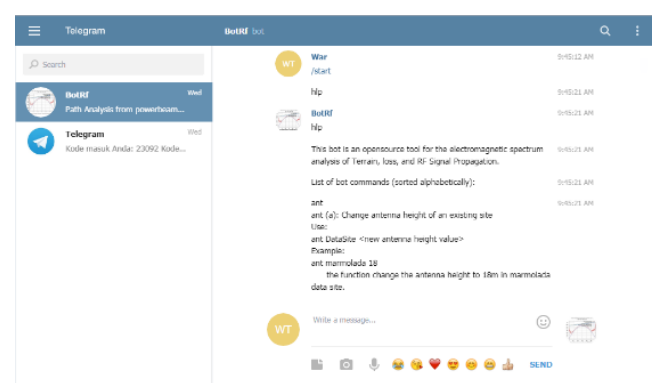

Gambar 5. Tampilan utama BotRf Telegram

\section{Hasil dan Pembahasan}

Dari hasil survey lapangan dan simulasi beberapa kali menggunakan bot telegram maka didapatkan hasil dan pembahasan sebagai berikut.
Gambar 4 menunjukkan tampilan utama dari botrf dimana ketika botrf dibuka kita bisa menggetikkan help untuk mengetahui command prosedur yang terdapat pada botrf tersebut. Selanjutnya ketika telah mengetahu prosedur-prosedur perintah dari bot maka kita masukkan parameterparameter yang akan kita gunakan untuk mengetahui kondisi hasil dari link point to point antara kedua device. Parameter-parameter tersebut dapat berupa antenna, tinggi, frekuensi dan lain sebagainya.

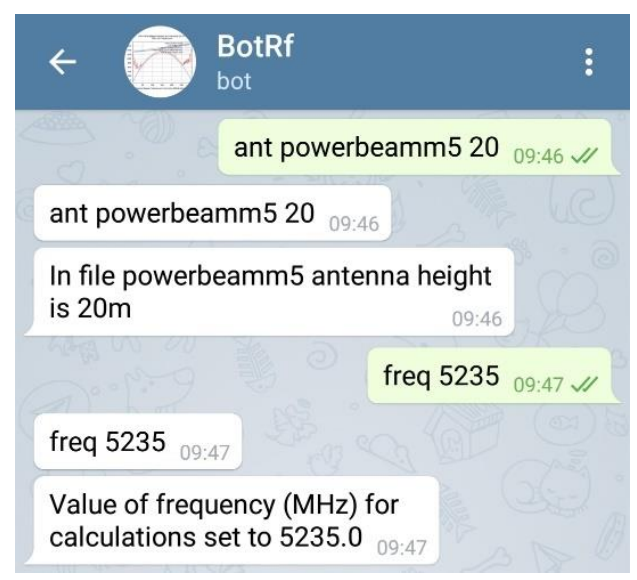

Gambar 6. Input Antenna, Tinggi dan Frekuensi

Pada gambar 6 menunjukkan proses input parameter berupa jenis antena yaitu jenis Powerbeam M5 Produk dari vendor Ubiqiti Network untuk kedua sisinya. Untuk inputan antenna dapat digunakan perintah ant [jenis antenna] [tinggi antenna] contoh: ant powerbeamm5 20, maka botrf akan membalas seperti yang tertera pada gambar 4. Kemudian input parameter frekuensi disini kita menggunakan f rekuensi $5.235 \mathrm{Ghz}$, 
untuk inputan frekuensi menggunakan perintah Freq [frekuensi yang digunakan] contoh freg 5235, maka botrf akan membalas sesuai pada gambar 7

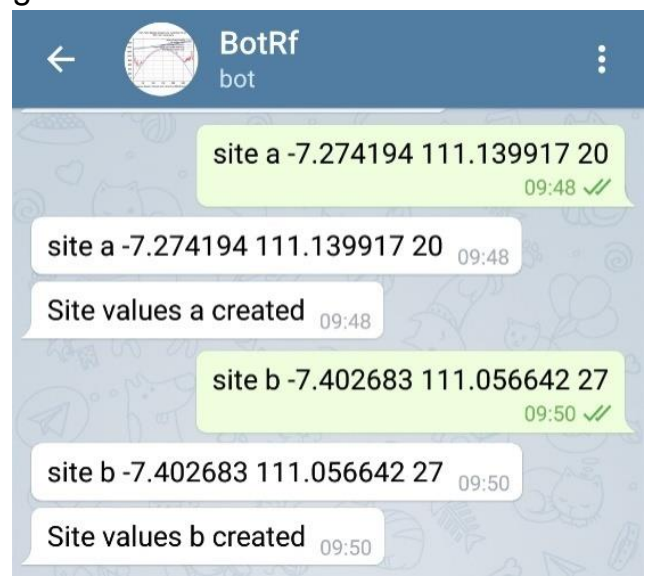

Gambar 7. input titik kordinat kedua sisi device

Gambar 7 menunjukan proses input parameter lokasi berupa titik kordinat. Untuk dapat memeproleh titik kordinat dapat diperoleh melalui google map jika menggunakan PC dalam menggunakan telegram. Kelebihan dalam menggunakan Telegram di mobile device adalah kita dapat memanfaatkan GPS yang terdapat pada mobile device tersebut sehingga secara otomatis dan presisi dengan titik kordinat yang didapat melalui GPS langsung pada mobile device tersebut. Untuk parameter ini kita menggunakan perintah site [nama titik 1] [latitude] [longitude] [tinggi antenna] begitu juga pada sisi kedua, contoh site lokasi A -7.274194 111.13991720.

Proses selanjutnyaadalah menghitung atau kalkulasi antara titik (a) dengan titik (b) untuk kalkulasi dapat dilihat pada gambar 8 dibawah:

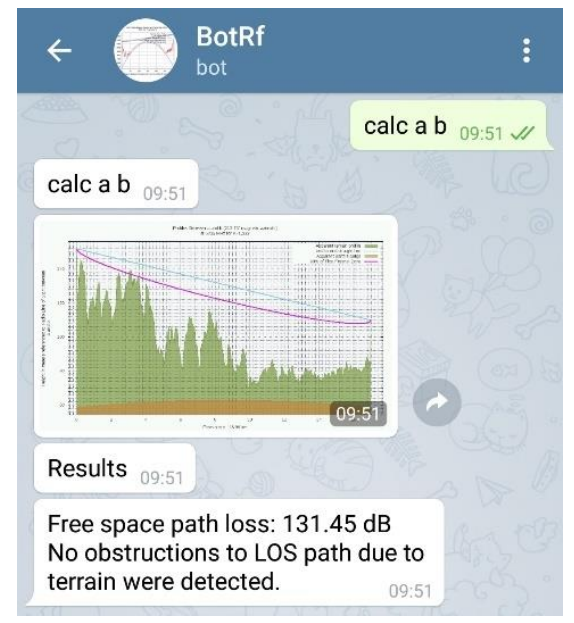

Gambar 8. Kalkulasi antara Sita(a) dengan Site (b)

Perintah untuk kalkulasi sebagai berikut calc [sita a] [site b] contoh calc a b maka botrf akan menampilkan perhitungan dengan menunjukkan hasil berupa grafik beserta keteranganketerangan lainnya seperti ditunjukkan gambar 9

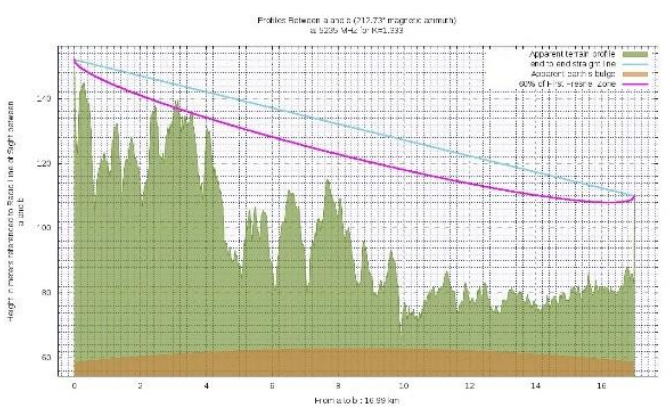

Gambar 9. Hasil Kalkulasi antara titik a menuju titik b

Gambar diatas menunjukkan hasil kalkulasi perhitungandari antara titik a ke titik $b$ dengan parameter yang dimasukkan berupa jenis antenna, tinggi antenna, dan titi kordinat dari kedua sisi. 
Untuk memperoleh detail dari grafik gambar 7 dapat digunakan perintah rep [nama site 1] [nama site 2], contoh rep a $\boldsymbol{b}$ maka didapatkan hasil sebagai berikut:

Path Analysis from $a$ to $b$

Distance between a and b: $16.99 \mathrm{~km}$

Transmitter site: a

Site location: $(-7.2742,+111.1399)(-7$

16'27"/+111 8'23")

Elevation: $132 \mathrm{~m}$ above sea level

Antenna height: $20 \mathrm{~m}$ above ground /

$152 \mathrm{~m}$ above sea level

Azimuth to b: 212.73 degrees

Depression angle to $b:-0.1990$ degrees

Receiver site: $\mathrm{b}$

Site location: $(-7.4027,+111.0566)(-7$

24'9"/+111 3'23")

Elevation: $83 \mathrm{~m}$ above sea level

Antenna height: $27 \mathrm{~m}$ above ground /

$110 \mathrm{~m}$ above sea level

Azimuth to a: 32.74 degrees

Elevation angle to a: +0.0844 degrees

Analysis model: Longley-Rice

Parameters used in this analysis:

Earth's Dielectric Constant: 15.000

Earth's Conductivity: 0.005

Siemens/meter

Atmospheric Bending Constant ( $\mathrm{N}$ -

units): 301.000 ppm

Frequency: $5235 \mathrm{MHz}$

Radio Climate: 5 (Continental

Temperate)

Polarization: 0 (Horizontal)

Fraction of Situations: $50.0 \%$

Fraction of Time: $50.0 \%$

Summary for the link between $a$ and $b$ :

Free space path loss: $131.45 \mathrm{~dB}$

Longley-Rice path loss: $131.41 \mathrm{~dB}$

Attenuation due to terrain shielding: -

$0.04 \mathrm{~dB}$

Mode of propagation: Line-Of-Sight

Mode
Longley-Rice model error code: 0

ErrorMessage[0]:

"No error"

No obstructions to LOS path due to terrain were detected.

Dari detail grafik menunjukkan jarak antara titik a ke titik b sejauh 16.99 $\mathrm{km}$ diikuti dengan keteranganketerangan lainnya seperti tinggi antenna diatas permukaan laut, path los, polarisasi dan lain sebaginya dan juga hasil akhir dengan ditunjukkan tidak adanya hambatan dari kedua sisi sehingga sangat mungkin untuk dapat di pasang radio wireless pada titik tersebut.

\section{Simpulan}

Penggunaan botrf ini membantu dalam simulasi pemasangan dan penentuan titik dimana radio wireless akan dipasang. Dengan mensimulasi terlebih dahulu kita bisa mengetahui suatu hasil apakah antara titik satu dengan titik yang lainnya tidak ada hambatan ketika kita memasang radio wireless pada kedua titik tersebut. Dan ini membuat waktu lebih efektif dan efisien. Dari penelitian diatas dapat disimpulkan bahwa penggunaan bot telegram sangatllah mudah dan fleksibel terhadap system operasi apapun dibandingkan dengan tool-tool simulator yang lain, selain itu bahwa titik a (Gobang, Banyurip, Jenar) yang merupakan daerah rural dan titik $b$ (Ngrampal sragen kota) pada titik kordinat diatas maka sudah pasti dapat di koneksikan tanpa harus mempraktikkan secara langgsung sehinggga akan lebih efektif dan efisien dari segi waktu dan biaya. Untuk kedapannya mungkin bisa dikombinasikan dengan tool-tool lain seperti google earth dan lain-lain sehingga mempermudah para pekerja jaringan dalam melakukan simulasi. 


\section{Daftar Pustaka}

Afdhal, Elizar. IEEE 802.11ac sebagai Standar Pertama untuk Gigabit Wireless LAN. JURNAL REKAYASA ELEKTRIKA. 2014. Vol $11: 36-44$

Manurang Fenni A, Naemah Mubarakah. Analisa Link Budget Untuk Koneksi Radio WLAN 802.11B Dengan Lmenggunakan Simulasi Radio Mobile. SINGUDA ENSIKOM. 2014; vol(7): 82

Oba M.Z, A.A Yeni. Data Rates Performance Analysis ofPoint to
Multi-Point Wireless Link in University of Ilorin Campus.IRJET. 2016. Vol 03:25

Sastrawangsa Gde. Pemanfaatan Telegram Bot Untuk Automatisasi Layanan Dan Informasi Mahasiswa Dalam Konsep Smart Campus. KNSI .2017 hal: 772-776 Zennaro Marco, authorMarco Rainone, Ermanno Pietrosemoli. Radio Link Planning Made Easy with a Telegram Bot. LNICST.2016.vol 195 